\title{
PERGUNTAS NA SALA DE AULA: UMA CLASSIFICAÇÃO TEXTUAL-INTERATIVA
}

\author{
José Carlos Lima dos Santos \\ Andréia Silva Araujo \\ Raquel Meister Ko Freitag
}

\begin{abstract}
RESUMO
Este texto apresenta uma análise do uso das perguntas na sala de aula numa perspectiva textual-interativa. Partimos da revisão de estudos que tratam de estratégias interrogativas na fala a fim de elaborarmos uma proposta de classificação destas no discurso de sala de aula.
\end{abstract}

PALAVRAS-CHAVE: estratégias interrogativas, sala de aula, prática discursiva.

\section{Introdução ${ }^{1}$}

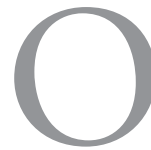

ato de perguntar e/ou questionar ${ }^{2}$ faz parte da condição humana, posto que desde a antiguidade o homem se ocupa em obter respostas relacionadas com as diversas áreas do conhecimento, isto é, a construção do conhecimento tem ligação direta com o ato de perguntar/ questionar. No contexto escolar, este ato possui um papel imprescindível, evidenciando, assim, a necessidade de se atentar para a forma como o ato de perguntar/questionar ocorre em sala de aula.

1 Este trabalho está vinculado ao projeto Procedimentos discursivos na fala e na escrita de Itabaiana/SE (FREITAG, Raquel Meister Ko. Procedimentos discursivos na fala e na escrita de Itabaiana/SE. [Projeto de pesquisa]. Universidade Federal de Sergipe/ Fundação de Apoio à Pesquisa e à Inovação Tecnológica do Estado de Sergipe, 2007).

2 Não vamos tomar as palavras perguntar e questionar como sinônimas; mesmo tendo aproximação de sentido, elas não possuem exatamente a mesma carga semântica. $\mathrm{O}$ ato de perguntar fica apenas no plano de esperar uma resposta, seja por falta de informação, seja para testar o conhecimento de alguém; já o questionamento leva a resposta para o plano da discussão, verificação, da dúvida. 
No discurso da sala de aula, o ato de perguntar/questionar é uma estratégia interrogativa indispensável ao professor, que pode não só ser utilizada para desenvolver o assunto abordado, funcionando como um recurso discursivo e argumentativo, como também para interagir com o aluno, levando-o a questionar e a refletir sobre um determinado assunto. Entretanto, isso só será possível se o professor adotar maneiras diferentes de interrogar e abrir espaço para questionamentos e discussóes durante a aula.

Quando falamos em estratégias interrogativas, estamos nos referindo aos diversos procedimentos discursivos de que se vale o locutor para fazer uma pergunta. Estes procedimentos se manifestam de várias formas e não se reduzem apenas ao ato de perguntar e se requerer uma resposta, já que estão relacionados ao desenvolvimento do tópico discursivo.

Com base em estudos sobre perguntas, neste trabalho analisamos as formas de interrogação no discurso de sala de aula, a fim de identificar quais estratégias textuais-interativas existem em sala de aula durante o processo de pergunta e resposta e se há algum traço de similaridade entre o que a gramática elege como forma de interrogar e o que ocorre em contexto real de uso, neste caso, a sala de aula. A partir de um cotejamento entre as tipologias de perguntas já existentes, tanto no discurso simétrico, como no assimétrico, propomos uma aplicação dessas classificações em relação ao tópico discursivo de sala de aula.

Utilizamos para a análise o corpus intitulado "O Estudo da Interação Discursiva em Aulas do Ensino Fundamental”, organizado por Santos ${ }^{3}$, Os dados encontrados no corpus são observados qualitativamente, com vistas ao mapeamento das funções e subfunções das estratégias de interrogação encontradas no discurso de sala de aula. A seguir, discorremos sobre a abordagem textual a partir de dois temas: procedimentos discursivos e tópico discursivo. $\mathrm{Na}$ seção seguinte, realizamos uma revisão dos estudos sobre perguntas; para tanto, subdividimos esta seção em duas: perguntas na fala e perguntas no discurso da sala de aula. Na sequência, apresentamos uma abordagem unificada para as perguntas e, por fim, as consideraçóes finais.

3 SANTOS, Maria Francisca Oliveira. A interação em sala de aula. Ed. Recife: Ediçóes Bagaço, 2004. 


\section{A abordagem textual interativa}

Para esta análise, assumimos uma concepção de língua baseada na interação e no uso, focando o texto falado não de forma isolada, mas integrado a fatores pragmáticos, ou seja, o texto é visto como resultado da interação verbal e por fatores que estão envolvidos no momento da enunciação.

Estratégias interrogativas são os diversos procedimentos discursivos adotados pelo locutor/interlocutor para fazer perguntas. O que se entende por procedimentos discursivos, aqui, dialoga com o entendimento de Barros ${ }^{4}$, de que "procedimentos cumprem as funções de construção da conversação e de estabelecimento da interação entre sujeitos, isto é, as funçôes interacionais de persuasão e argumentação e de envolvimento passional dos participantes da conversaçáo". Os diversos usos de procedimentos discursivos instauram construçóes argumentativas diferentes e, consequentemente, diferentes papéis conversacionais e diferentes tipos de conversação. A troca de papel conversacional está relacionada à construçấo de papel social. No caso da sala de aula, não há troca de papel conversacional, o professor é sempre professor; porém, há como relacionar as perguntas com as relaçôes de poder que são assumidas nesse contexto pelos interactantes presentes no âmbito de sala de aula, que é o que configura a relação professor-aluno.

O papel social do falante não está apenas relacionado à posiçáa que ocupa na sociedade, mas também decorrente do modo como se constrói nos procedimentos discursivos que se configuram como elementos persuasivo-argumentativos dentro do contexto da conversação. As perguntas de sala de aula são uma prática discursiva, vinculada com o contexto de interatividade e ao tópico.

Costuma-se definir a noção de tópico a partir de dois níveis de análise: o frasal e o discursivo. ${ }^{5}$ A noção adotada é a de tópico discursivo, por ser uma construção que se realiza dentro da interação verbal, através das negociaçóes efetivadas pelos interlocutores.

4 BARROS, Diana Luz Pessoa de. "Procedimentos e recursos discursivos da conversaçáo". In: DINO, Preti. Estudos de lingua falada: variaçóes e confrontos. São Paulo: Humanitas, 1998, p. 48.

5 MARCUSCHI, Luiz Antônio. Produção textual, análise de gêneros e compreensão. São Paulo: Parábola, 2008. 
[...] em qualquer interação verbal espontânea entre indivíduos em qualquer situaçáo da vida diária, apesar de alguém sempre propor um tópico, esse alguém nunca terá a certeza de conduzir o tópico até o final por conta própria, pois sempre haverá que contar com a participação do outro. Quando se analisa o tópico discursivo, não se trata de uma simples análise de conteúdo, mas dos procedimentos para encadear os conteúdos. [...] adoto a noção de tópico discursivo, designando com isso o tema discursivo, aquilo sobre o que se está falando num discurso [... ] não necessariamente considerando a frase. ${ }^{6}$

Não basta apenas considerar o texto desvinculado do discurso, uma vez que aquele se dá a partir deste, podendo-se verificar as diversas estratégias usadas pelo locutor para encadear os conteúdos. Assim, no caso das perguntas, não é suficiente apenas identificar as formas como se apresentam, mas também as diversas funçôes que podem assumir quando instauradas no discurso.

Givón ${ }^{7}$ apresenta uma definição de tópico discursivo fundamentalmente cognitiva. Por ser complexo, o tópico não pode ser considerado apenas no domínio da oração, embora seja identificado neste, mas como um sistema funcional complexo identificado por hierarquia de acessibilidade, discutindo a ideia de haver uma organização discreta no discurso, na qual o sujeito é mais tópico que o objeto direto, e este mais tópico que o indireto.

Outro ponto que merece ser considerado em relação à função do analista assenta-se no fato de que a propriedade de centração deve nortear toda análise, já que através desta, segundo Jubran, "o analista identifica o tópico proeminente sobre o qual se discorre em cada momento da interlocução, delimitando segmentos tópicos, cuja organização pode ser analisada tanto no plano intratópico quanto no intertópico". ${ }^{8}$ No plano intratópico, para esta autora, são investigadas estratégias de construção textual, como repetição, correção, para-

6 MARCUSCHI, op. cit., p. 134-135.

7 GIVÓN, Talmy. Syntax: An introduction. Amsterdam/Philadelphia:John Benjamins, 2001, p. 198.

8 JUBRAN, Clélia Cândida Spinardi. “Tópico discursivo”. In: JUBRAN, Clélia Spinardi; $\mathrm{KOCH}$, Ingedore (orgs.). Gramática do português culto falado no Brasil. Campinas: Editora da Unicamp, 2006, p. 95. 
fraseamento e parentetização. Já no intertópico, o foco recai sobre as relaçôes de sequenciamento, ou interpolação de tópicos na linearidade textual, como também as relações hierárquicas entre super e subtópicos.

O tópico pode se manifestar tanto vertical, na hierarquia, como horizontalmente na linearidade do discurso. Desta forma, as perguntas analisadas nesta investigação estão sempre relacionadas com o tópico discursivo. Nossa proposta é analisar, identificar e relacionar as perguntas com a introdução, a continuidade, a reintrodução e a mudança de tópico, considerando os planos inter e intratópicos, sem se eleger um plano desse como superior, pois como fundamentam os princípios da perspectiva textual-interativa "os elementos integrantes do texto comportam simultaneamente funçóes textuais e interacionais, que se combinam em graus variáveis, ora com dominância de uma função sobre outra, ora com um contrabalanceamento entre as duas". ${ }^{9}$ Assim, esta análise implicaria um contínuo e não em classes discretas, umas independentes das outras.

\section{Estudos sobre as perguntas}

Tradicionalmente, a gramática normativa costuma classificar as perguntas em parciais ou gerais, e diretas ou indiretas. As diretas são independentes e caracterizadas por entonação ascendente no final e, quando parcial, começa por um vocábulo interrogativo. E as indiretas são dependentes e destituídas de entonação interrogativa, não requerem uma resposta imediata e começam, geralmente, por um pronome ou advérbio interrogativo. Cunha e Cintra, dentro da perspectiva normativa, postulam que, para se estudar as estruturas interrogativas, há que se considerar, em primeiro lugar, a entonação e se a frase inicia ou não por advérbio ou pronome interrogativo, pois são estes fatores que irão diferenciar uma frase declarativa de outra afirmativa. ${ }^{10}$ Para o primeiro tipo entonação -várias características rítmicas e prosódicas são apresentadas para estabelecer essa distinção:

9 JUBRAN, op. cit., p. 95.

10 CUNHA, Celso; CINTRA, Lyndley. Nova Gramática do Português Contemporâneo. Rio de Janeiro: Nova Fronteira, 2001, p. 170. 
a) espera sempre uma resposta categórica de sim ou não;

b) o ataque da frase começa por um nível tonal mais alto do que a oração declarativa;

c) na parte medial do segmento melódico, haver uma queda de voz, que, embora seja mais acentuada do que nas oraçóes declarativas, não altera o caráter ascendente desta modalidade de interrogação;

d) subir a voz acentuadamente na última vogal tônica, ponto culminante da frase; em seguida, sofrer uma queda brusca, apesar de se manter em nível tonal elevado. ${ }^{11}$

Há, para essa distinção, outras formulações, como a comparação da curva da oração declarativa com a da interrogativa. Neste cotejamento, os autores afirmam que a curva de ambas as oraçóes se assemelha por terem a parte inicial ascendente e medial relativamente uniforme. A principal distinção, nesta categoria de análise, ocorreria na parte final, que na declarativa é descendente, e na interrogativa, ascendente.

Para as frases iniciadas com pronome interrogativo, os autores sinalizam dois tipos principais, a saber:

a) o ataque da frase que, iniciado em um nível tonal muito alto, sobe, às vezes, bruscamente, até a primeira sílaba tônica, sílaba esta que, na maioria dos casos, pertence ao pronome ou ao advérbio interrogativo, ou seja, ao elemento que realiza a função interrogativa da oração;

b) a curva melódica, que, após a primeira sílaba tônica, decresce progressivamente e de maneira mais acentuada do que nas frases declarativas ${ }^{12}$

É suficiente, para Cunha e Cintra, ao se identificar uma oração interrogativa, ater-se a aspectos tonais da frase. Náo há referência a discurso, texto e

$\begin{array}{ll}11 & \text { Ibd., p. } 171 . \\ 12 & \text { Ibd., p. } 172 .\end{array}$ 
contexto, e, muito menos, ao tópico discursivo. Esta classificação de Cunha e Cintra se repete nas demais gramáticas normativas; explanamos sobre a classificação de perguntas na fala e no discurso de sala de aula, respectivamente.

\section{Perguntas na fala}

A proposta de classificação de Fávero, Andrade e Aquino ${ }^{13}$ estabelece um critério baseado na função, natureza e estrutura das perguntas. As autoras frisam que há uma relação intrínseca entre uma pergunta e uma resposta, ou seja, a pergunta faz restrição sintática à resposta, antecipando-a. Todavia, essa restrição não ocorre de forma absoluta, haja vista que uma pergunta pode ser respondida com outra pergunta. O quadro 1 sumariza a proposta de classificação.

\begin{tabular}{l|l|l}
\hline $\begin{array}{c}\text { QUANTO À FUNÇÃO } \\
\text { NA ORGANIZAÇÃO } \\
\text { TÓPICA }\end{array}$ & $\begin{array}{c}\text { QUANTO À } \\
\text { NATUREZA }\end{array}$ & QUANTO À ESTRUTURA \\
\hline $\begin{array}{l}\text { introduçáo de tópico } \\
\text { - continuidade de tópico } \\
\text { reintrodução de tópico } \\
\text { mudança de tópico }\end{array}$ & $\begin{array}{l}\text { pedido de informação } \\
\text { pedido de confirmaçáo } \\
\text { pedido de esclarecimento }\end{array}$ & $\begin{array}{l}\text { Ps fechadas (ou de sim/ não) } \\
\text { Ps abertas (ou sobre algo) } \\
\text { Ps retóricas }\end{array}$ \\
\hline
\end{tabular}

Quadro 1: Proposta tipológica das perguntas de Fávero, Andrade e Aquino. ${ }^{14}$

Quanto à função, as perguntas servem para introduzir o tópico, pois é comum iniciarmos uma fala fazendo uma pergunta. Pode-se constatar este fato no excerto (1), já que, antes de iniciar o tópico de que tratará aula, a professora faz uma pergunta, a fim de estabelecer um elo entre o assunto dado anteriormente e que vai ser introduzido.

(1) L1 - é .. (( depois da intervenção de L2, a professora fará a introdução da aula do dia recapitulando aula anterior. )) na aula passada nós fizemos O QUÊ? a leitura de reconhecimento sobre divisão de seres vivos ... CERTO? VOCÊS ... grifando ... (( neste momento L1 faz uma pausa de procura e algo mais específico no material que arrumava anteriormente. Durante

13 FÁVERO, Leonor Lopes; ANDRADE, Maria Lúcia da Cunha Victório de Oliveira; AQUINO, Zilda Gaspar Oliveira de. "O par dialógico pergunta - resposta”. In: JUBRAN, Clélia; $\mathrm{KOCH}$, Ingedore (org.). Gramática do português culto falado no Brasil. Campinas: Editora da Unicamp, 2006.

14 Ibd, p. 133. 
este tempo os alunos conversam entre si e, dois dos alunos que se encontram mais próximos da professora brincam todo tempo trocando bolinhas de papel.)) (p. 64, linha 2491)

Em (1), a pergunta facilita a introdução do tópico. Essa facilitação é decorrente do fato de haver uma preocupação por parte da professora não só de dar sequência às aulas, mas também fazer com que o aluno associe o que vai ser dito com o que foi falado antes.

Outro tipo de pergunta que é classificada com relação à função tem a ver com a continuidade de tópico. As perguntas que se encaixam neste critério se relacionam diretamente com o tópico em desenvolvimento, fazendo com que este progrida.

(2) [...] então para classificar os seres com todas aquelas características... número de células ... especificação da célula ... o tipo de nutrição .. ((a professora gesticula apontando e dando leves toques no quadro como se quisesse demonstrar uma enumeração.)) e esta característica do ser procarionte vai demonstrar o quê? a SUA ... é:: a sua é a sua característica primitiva do ser ..certo? (p. 66, linha 2574)

A presença da pergunta em (2) colabora com desenvolvimento do tópico, por estar relacionada à explicação da professora. Este tipo de pergunta serve de suporte para explicitação e desenvolvimento do conteúdo em andamento em sala de aula. Outra forma de classificação de pergunta com relação à função diz respeito à reintrodução do tópico, pois ocorre de se introduzir na fala uma pergunta quando se tem a intenção de querer mudar o tópico em andamento, como em (3).

(3) L10 ( ) ((L10 insiste em tomar o turno de fala e levanta-se outra vez falando junto à professora, isto é, ele não consegue tomar a palavra falando do lugar onde se encontra. L1 confirma suas indagaçóes/colocaçóes com o movimento positivo de cabeça. Chamamos indagaçôes/colocaçôes, porque L10 levanta-se para perguntar ao mesmo tempo em que parece fazer afirmação. É bom anotarmos que concluímos as atitudes de L10 através de seus movimentos e posturas))

L1 - pssiiuu ( ) então como característica do/.../ da classe aracnídea são o quê ? escorpiões?... (p. 75, linha 2924)

Depois de haver uma quebra no desenvolvimento do turno, por conta das interrupçóes dos alunos, a professora retoma o assunto com uma pergunta 
relacionada com o que estava falando antes, configurando-se em uma retomada do tópico que havia sido interrompido.

Ocorre também de haver um redirecionamento do tópico que está em andamento por meio de uma pergunta, dando-se um novo rumo ao discurso. Em (4), um aluno interrompe a fala da professora, que estava discorrendo sobre as características do reino monera, com uma pergunta, por achar que esta estava falando muito.

(4) L1 - carioteca ... então falta carioteca na célula dos moneras ... por isso que o núcleo não é organizado ... e por isso que eles são procariontes (( L1 ao terminar as explicaçóes sobre as sétima questão, dirigi-se para o birô e apanha o livro que havia deixado sobre ele.)) ... oitava questão ... oitava questão ... com que nome as bactérias de forma arredondada são chamadas?

L2 - ( )

L1 - DI?

L2L3 - corpos

L1 - de corpos .... as bactérias arredondadas são chamadas de corpus...

L10 - a professora tomou FORT VITE FOI? não se cansa não ... ali em pé direto ( ) ((risos))

L11 brincadeira ( ) oxem ... tu é cheio de onda veio.... (p. 44, linha 1683)

Houve, com essa pergunta feita pelo aluno, uma mudança de tópico, uma vez que o assunto que estava sendo abordado foi interrompido até a professora retomá-lo, o que é feito mais adiante.

No que tange à natureza, as perguntas podem ser feitas para pedir informação, confirmação e esclarecimento. $\mathrm{O}$ uso de perguntas para pedir informação pode ser feito com o objetivo de saber uma resposta por necessidade do locutor. Em (5), a professora, ao começar apagar o quadro, sente a necessidade de saber se existe alguém copiando ainda, para que não fique prejudicado.

(5) L1 conversa rapidamente com um aluno da frente. Agora, alguém chama a aluna Andressa Karina, todos olham para a porta, e por um breve instante a aula é interrompida. Entáo, L1 começa a apagar a primeira parte do quadro, e enquanto pergunta)) tem alguém ainda copiando esse lado?

$\mathrm{L} 2-\mathrm{eu} . .$.

L3 - eu ... (p. 19, linha 699)

A pergunta feita pela professora demonstra sua preocupação em saber se há algum aluno copiando. Desse modo, evidencia-se a necessidade de fazer a 
pergunta e receber a resposta, para poder dar continuidade em suas atividades. No caso de confirmação, as perguntas são elaboradas para que o interlocutor sustente o que foi falado. Também ocorre quando quem fez a pergunta não concorda com resposta para certifica-se da resposta correta.

(6) L1 - sabe o que é habitat? Gente ouve tanto falá né? habitat ... que qui é habitat? é

L2 [de baixo.

L1 - é habitat? ... que qui é habitat gente?

L2 a moradia de família ( ) (( L1 estava escrevendo algo no quadro e não escutou o aluno, tornando a perguntar))

L1 o que é habitat gente? ... tâo comum falar em ecologia ultimamente ... e habitat? que é que é habitat? ... é o quê? é comida? é lugar? é o quê?

L2L3 - lugar...

L1 - lugar .... lugar onde?

L8 - onde os animais habitam (p. 23, linha 850)

Em (6), a professora formula uma pergunta aos alunos querendo saber o conceito de habitat. Quando recebeu a resposta, fez a pergunta de novo a fim de que os alunos confirmassem o que haviam dito antes, para que ela tivesse certeza de que sabiam efetivamente a resposta.

Por fim, ainda quanto à natureza, as perguntas podem ser elaboradas com o intuito de se pedir um esclarecimento. Isso ocorre quando o ouvinte não consegue entender o que foi perguntado e pede que a reposta seja refeita em parte ou parcialmente, como em (7).

(7) ... pra garantir que as duas novas bactérias sejam exatamente igual à ela (sic)?

L4 - multiplicar...

$\mathrm{L} 1$ - quase isso ... (( a professora faz um movimento de mais ou de menos com a mão direita para que L4 perceba que sua resposta está aproximando-se da resposta correta.)) ... não é multiplicar ... que é que ela faz?

\section{L5 - como é ? com é professora?}

L1 - hã?

L5- como é?

L1 - antes de se dividir ela vai se dividir em duas ... mas antes de se dividir pra garantir que essas duas novas bactérias sejam exatamente iguais a ela .... o que é que essa bactéria faz? ( p. 34, linha 1278) 
Em (7), o aluno não entendeu a fala da professora e pede para que ela repita de novo. Ao fazer, esta reformula a pergunta a fim de facilitar seu entendimento.

A terceira categoria de classificação está relacionada com a estrutura. Por essa via, as perguntas podem ser fechadas, (de sim ou não), abertas (sobre algo) e retóricas. As perguntas fechadas são aquelas que exigem como resposta um 'sim' ou 'não'. As respostas, dependendo do contexto, podem ser diferentes, entretanto, elas retomam ou assumem o significado de 'sim' ou 'não', como em (8).

(8) L1 - elas vivem associadas a quem?

L2 - aos humanos (( fala bem baixinho, demonstrando insegurança))

L1 - só aos humanos? ... elas vivem associadas a outros seres vivos ... seres humanos ou ( ) né? e elas causam mal a esses outros seres?

L2L3L4 ... não ... (p. 31, linha 1167)

A pergunta de (8) foi formulada para ter como resposta um 'sim' ou 'não'. Nota-se, por este contexto, que não há possibilidade de outras respostas por ser uma pergunta fechada, restringindo o tipo de resposta a ser dada.

Já as perguntas abertas têm como característica uma informação sobre algo. Elas são geralmente iniciadas por um termo interrogativo sobre o qual recai o escopo da resposta.

(9) (( L1 escreve o termo "algas" no quadro e vira-se para frente cruzando os braços)) quem lembra como é que a gente chama também as algas AZUIS? (p. 37, linha 1420)

Em (9), há a presença de dois termos interrogativos, 'quem' na função de sujeito, e 'como' adjunto adverbial de modo, o que indica que a pergunta exige dois tipos de resposta. A presença de termos interrogativos faz com que as repostas sejam direcionadas para eles, ou seja, as respostas são dadas, tendo como foco os termos interrogativos.

Quanto às perguntas retóricas, ainda levando em conta a estrutura, a classificação de Fávero, Andrade e Aquino ${ }^{15}$ diverge da proposta de Freitag e Araujo ${ }^{16}$, a qual veremos a seguir, em alguns pontos. As primeiras autoras

15 FÁVERO et alii, op. cit.

16 ARAUJO, Andreia Silva; FREITAG, Raquel Meister. Ko. "Estratégias de interação na fala: funçôes das perguntas na fala de Itabaiana/SE". Interdisciplinar: Revista de Estudos em Lingua e Literatura, v. 10, n. especial, p. 107-120, 2010. 
tratam as perguntas retóricas como sendo perguntas, enquanto as segundas, ao estudá-las dentro do contínuo da gramaticalização, não as consideram exatamente como perguntas, mas como estágio de desenvolvimento de marcadores discursivos, que, na concepção das autoras, são construçôes gramaticalizadas que funcionam como estratégias de interação e sequenciação na organização textual.

O estudo de Freitag e Araujo tem como foco a gramaticalização das estratégias interrogativas até marcadores discursivos dentro de um contínuo. As autoras delineiam como se dá o percurso que origina o contínuo: pergunta plena > pergunta semirretórica > pergunta retórica até os marcadores discursivos. O curso de mudança envolve "processo de abstratização, cujo estágio inicial é em contextos de perguntas plenas, passando ao uso em contextos totalmente interrogativos, pergunta semirretórica, em que o falante responde à sua própria pergunta, e por fim, a construção encontra-se em contexto interrogativo totalmente retórico". ${ }^{17}$ Neste sentido, Araujo e Freitag ${ }^{18}$ não tratam as perguntas retóricas como uma perguntas literalmente, já que, neste estágio, estas assumem função de marcador discursivo, diferindo da classificação de Jubran, ${ }^{19}$ a qual enquadra pergunta retórica como uma pergunta, de acordo com a categoria estrutural.

Retomando o contínuo proposto por Araujo e Freitag ${ }^{20}$, são consideras plenas as perguntas que exigem uma resposta ou uma confirmação do interlocutor. Para esse tipo de pergunta se obtém reposta do interlocutor. Essas perguntas ocorrem no momento da enunciação que se estabelece entre os interlocutores, sendo, portanto, sua ocorrência típica da língua falada. Quando ocorre na escrita, é através do discurso reportado, pelo qual se procura transcrever o diálogo para a língua escrita, ocorrendo, assim, uma simulação da língua falada em tempo real de uso.

O excerto (10) caracteriza o que é definido aqui como pergunta plena. A gramática normativa caracteriza esse tipo de pergunta como sendo aberta ou fechada, direta ou indireta.

17 FREITAG, Raquel Meister Ko. "Estratégias gramaticalizadas de interação: marcadores discursivos revisitados". Revista Virtual de Estudos da Linguagem, ReVEL, vol. 7, n. 13, 2009, p. 7.

18 ARAUJO; FREITAG, op. cit.

19 JUBRAN, op. cit.

20 ARAUJO; FREITAG, op. cit. 
(10) ... L1 - foi aquele exemplo que eu dei/.../ por exemplo vamu imaginar que essa bactéria aqui somando tudo o que ela tem/.../ tem número que fica mais fácil a gente imaginar né? da gente entender /.../ vamu imaginar que somando tudo que ela tem SO:MA:: DEZ(( L1 escreve o número 10 ao lado do desenho da bactéria))... vamos dizer ... dez unidades... dez estruturas ... ANTES de se dividir ela fica com quantos?

\section{L2 - vinte.[...]}

L1 - com vinte ... então ela dobra tudo o que ela tem ... então ela vai ... deixa de ter dez ... só na hora de se reproduzir ... ela passa a ter vinte ... ela tinha dez ... quando se divide em DUAS ... cada um:a vai ter quantas? vou fazer menor ... ((L1 desenha a figura de uma outra bactéria ao lado da que estava desenhada, porém acha-a grande demais, por isso apaga-a para refazê-la, desta vez um pouco menor e desenha mais uma bactéria.)) dez...tá? então quando ela se dividir cada uma dessas bactérias vai ter quantas unidades ... assim dizendo? dez ...

... aquela tinha dez ... tá? então os passos da divisão binária são... primeiro a bactéria dobra ...cobra(sic)...duplica tudo o que ela tem e só depois ela se divide em duas exatamente iguais a ela ... entenderam?

L2L3L4 ... sim ... (p. 34, linha1308)

A exemplificação evidencia as respostas do interlocutor (aluno) para as perguntas em questão. Uma observação deve ser feita nesse sentido: mesmo a resposta estando marcada no discurso, essa classificação leva em conta os procedimentos discursivos do contexto de sala de aula como um todo. É importante pontuar que, embora as duas perguntas de (10) sejam plenas, as duas exigem respostas diferentes: a primeira é marcada pontualmente por um pronome interrogativo; a segunda é de sim ou não. Portanto, para identificar esse tipo de pergunta, não basta apenas observar a proposição em si, ou seja, verificar os aspectos frasais, mas levar em consideração também fatores semântico-pragmáticos.

Segundo Freitag e Araujo, ${ }^{21}$ a pergunta semirretórica é definida como sendo um tipo de pergunta que é feita e respondida pelo próprio falante. $\mathrm{O}$ que faz com que se perceba esse tipo de pergunta é o fato de o locutor não esperar pela resposta do ouvinte, ou seja, ele faz a pergunta e a responde com

21 Ibd. 
o objetivo de progredir o assunto que está ministrando. Neste caso, este tipo de pergunta pode assumir funçóes diferenciadas, assim como as perguntas retóricas. Uma das funçôes deste tipo de pergunta pode ser percebida em (11), quando a professora discorre sobre a classificação dos seres vivos:

(11) [...] ((caminhando em direção ao quadro, L1 o aponta falando)) ( ) pela língua que escritos EM latim ....têm sempre um significado .... os nomes não são escritos à toa ... quem escolhe esses nomes científicos ? os cientistas que primeiro descobrem .. ou então eles estudam cada espécie ... ou então eles estudam cada espécie ... por exemplo o: protozoário que causa a doença de chagas tem nomezinho meio complicado[...](p.11, linha365)

O que nos permite classificar a pergunta de (11) como semirretórica é o fato de o discurso ser continuado pela própria locutora (professora), ao responder sua própria pergunta. Sabe-se, pelo que o excerto mostra, que as perguntas semirretóricas não são apenas uma pergunta; estas

podem assumir a função de focalizador, pois por estratégia o falante solicita a atenção do ouvinte para certas partes do texto com o objetivo de ativar a informação na memória do ouvinte ou apenas para checar a compreensão do que foi dito. Este tipo de estrutura pode ser utilizado como um recurso para organizar ou ordenar segmentos textuais. ${ }^{22}$

$\mathrm{Na}$ literatura linguística, existem concepções diferentes no que diz respeito à pergunta retórica. Freitag e Araujo ${ }^{23}$ concebem a pergunta retórica como aquela que é formulada para não ser respondida, já que o ouvinte já conhece a resposta, bastando apenas recuperá-la na memória. Nesta função, a sequenciação do par dialógico, segundo o qual quem pergunta quer a resposta, é quebrada, servindo para o desenvolvimento do tópico ou para manter o contato com o aluno. Nesta categoria de análise, as autoras comungam com a proposta de Fávero, Andrade e Aquino quando asseveram que, na fala, estas "ocorrem quando o falante elabora uma P [ergunta] com o intuito de que o ouvinte não responda, porque aquele já conhece a $\mathrm{R}$ [esposta] e

$22 \mathrm{Ibd}$;

23 Ibd. 
é só uma questão de procurá-la na memória. Verifica-se que esse tipo de $\mathrm{P}$ [ergunta] é usado como recurso, entre outros, para manter o turno ou para estabelecer contato". ${ }^{24}$ Também possui caráter argumentativo, no sentido de estabelecer relação entre o locutor e o interlocutor. Aranha também corrobora com o exposto acima, ao postular o caráter argumentativo que possuem as perguntas retóricas: "pode parecer que esse artifício de 'dispensar' a resposta implica em uma ausência de interação, mas pelo contrário, a pergunta retórica afeta tanto quem formula quanto o seu interlocutor, ainda que em níveis diferenciados de envolvimento". ${ }^{25}$ De fato, existem evidências de que as perguntas retóricas se configuram numa estratégia importante de organização textual, já que atua como elemento de interação, ao mesmo tempo em que contribui para a construção da organização do tópico em desenvolvimento.

(12) ... e as algas azuis é interessante...elas vivem associadas/.../elas podem viver associadas com os fungos/.../a gente não estudou os fungos ainda né?((L1 que se encontrava próxima ao birô dirigi-se para o quadro, a fim de pegar o apagador e colocá-lo sobre o birô sem deixar seu turno de fala)) elas podem viver associadas com alguns fungos formado um ser vivo... um novo ser vivo que são os línqueis

L2-como? (( L2 - indaga num tom quase inaudível.)) (p.39, linha1486)

O tópico em desenvolvimento em (12) era sobre as algas azuis, que vieram logo após as bactérias. Pela ordem, sabe-se que a professora estava ensinando o reino monera. $\mathrm{Na}$ Biologia, existem cinco tipos de reinos que são agrupados de acordo com suas características. $\mathrm{O}$ monera, que é constituído por bactérias e algas azuis, é o primeiro. Sua característica tem a ver com o fato de as células dos organismos que fazem parte desse grupo serem procariontes, ou seja, o núcleo das células é desprovido da membrana que envolve o núcleo. Logo, de acordo com a sistematização que é exigida pelo conteúdo, viria o segundo reino, que é o protista, depois terceiro, o reino dos fungos. A professora ainda estava no primeiro. Também, pela análise do fragmento, observa-se que

24 FÁVERO, et alii, op. cit., p. 161.

25 ARANHA, Simone Dália de Gusmão. "Novas tecnologias no ensino de Língua Portuguesa: a propaganda da web como ferramenta pedagógica”. In: Anais do I Simpósio Mundial de Estudos de Lingua Portuguesa - I SIMELP. São Paulo, 2008. p. 6. 
ela continuou sua exposição sobre algas, não falou mais sobre fungos. Desse modo, ela elaborou uma pergunta que serviu de estratégia interativa, por não ter explicitado nada sobre fungos ainda. A pergunta foi feita e ao mesmo tempo não foi respondida; ou melhor, foi elaborada para não ser respondida, caracterizando o que se chama de pergunta retórica.

$\mathrm{Na}$ verdade, perguntas retóricas não são perguntas de fato, mas sim estratégias para estimular o envolvimento do ouvinte com a história, focando os processos de atenção e avaliação, podendo, também, funcionar como estratégia de encadeamento do tópico discursivo. Herring define perguntas retóricas como "qualquer elocução que é interrogativa na forma, porém, ao contrário de perguntas que requerem informação, as perguntas retóricas não solicitam respostas" ${ }^{26}$ Desta forma, ao se falar em tipologia de pergunta, há que se levar em conta, também, a resposta, já que esta delimita a pergunta que vai ser feita. Em suma, para esta autora, a pergunta retórica não é exatamente uma pergunta, elas são produzidas para simular e direcionar o envolvimento dos ouvintes, prendendo sua atenção, o que contribui para o desenvolvimento do tópico discursivo.

Levando-se em conta as demonstraçóes das tipologias de perguntas, pode-se ter uma ideia do que se tem na literatura linguística sobre o assunto. Os estudos resenhados foram realizados no discurso simétrico. No entanto, fica evidenciado que todas as perguntas mostradas aqui podem ser encontradas também no discurso assimétrico, haja vista o fato de terem sido encontradas no corpus sob análise e que ilustraram a exposição. Na próxima seção, discutimos os estudos sobre as perguntas na sala de aula.

\section{Perguntas no discurso da sala de aula}

O jogo de pergunta e resposta em sala de aula se configura, para Coracini, ${ }^{27}$ numa prática discursiva. A tipologia apresentada por esta autora, que, segundo ela, não é exaustiva, parte do professor em direção ao

26 HERRING, Susan. "The grammaticalization of rethorical questions in Tamil”. In: TRAUGOTT, Elizabeth; HEINE, Benrd (eds.) Approaches to grammaticalization. Philadelphia: John Benjamins, 1991, p. 257.

27 CORACINI, Maria José. "Pergunta-resposta na aula de leitura: um jogo de imagens". In: CORACINI, Maria José (org.) O jogo discursivo na aula de leitura: língua materna e língua estrangeira. Campinas, Pontes, p. 75-84. 
aluno. Embora a pesquisa de Coracini possua um viés teórico distinto, o que é considerado de sua pesquisa são os dados e a proposta de classificação de perguntas, na tentativa de se fazer uma aproximação com a abordagem aqui proposta. Coracini tenta mostrar, de acordo com sua perspectiva, que os alunos tendem a responder exatamente o que o professor quer, sendo raros os casos em que o aluno toma uma postura diferente. Esta acepção da autora em relação aos professores e alunos não é defendida aqui. A pesquisa de Coracini teve como foco principal as formas que as perguntas em sala de aula, feita pelo professor, assumem, e das respostas dos alunos a essas perguntas em aulas de leitura. Não foca efetivamente as perguntas em relação ao tópico, mas a relação professor-aluno.

Outro ponto que a investigação de Coracini procurou evidenciar foi se as perguntas que são utilizadas em sala de aula têm o mesmo propósito que tinhamna antiguidade, que era o da maiêutica socrática. A autora argumenta que as perguntas, na antiguidade, eram elaboradas para desenvolver, no discípulo, a capacidade de raciocinar e de elaborar soluçóes, baseadas na racionalidade, para as questóes que surgiam. No entanto, Coracini ${ }^{28}$ afirma que hoje só existe o vestígio dessa prática. As perguntas do professor são classificadas, de acordo com a proposta de Coracini, em dois tipos: as didáticas, que têm como objetivo estabelecer relação entre professor e alunos; e as comunicativas, que parecem escapar às preocupaçóes didáticas, mesmo fazendo parte da aula. Não significa que as primeiras não tenham um caráter comunicativo; o que as diferencia é o objeto e o momento da aula. As perguntas estão subdivididas em dois tipos principais, com algumas subdivisôes, resumidas no quadro 2.

\begin{tabular}{|c|c|c|c|c|c|}
\hline \multicolumn{6}{|c|}{ TIPOS DE PERGUNTA } \\
\hline \multicolumn{5}{|c|}{ DIDÁTICAS } & COMUNICATIVAS \\
\hline \multicolumn{3}{|c|}{ FACILITADORAS } & ANIMAÇĀA & VERIFICAR & \\
\hline ENCADEADAS & $\begin{array}{c}\text { MÚLTIPLA } \\
\text { ESCOLHA }\end{array}$ & $\begin{array}{c}\text { COM } \\
\text { LACUNAS }\end{array}$ & & & \\
\hline
\end{tabular}

Quadro 2: Proposta de classificaçáo das perguntas de Coracini

28 Ibd., p. 76. 
As perguntas encadeadas são caracterizadas por uma série de perguntas mais ou menos abertas e independentes pelo sentido. O que as unem é a linearidade do texto e o objetivo pedagógico.

(13) L1 ... então vamos lá ... o que é classificar?

L2 - separar em com classe ...

L1 - isso ... separar em classe ...separar EM?

L3 - Classe... (p. 2, linha 33)

O excerto (13) exemplifica o que é uma pergunta encadeada. Coracini ${ }^{29}$ defende que este tipo não exige nenhuma reflexão por parte dos alunos, já que basta apenas ter atenção e seguir o encadeamento da pergunta, tornando-se uma prática direcionada.

Se fosse em uma perspectiva textual-interativa que tivesse o tópico como referência, esta classificaçáo procuraria responder a seguinte pergunta: Qual a função da pergunta no desenvolvimento do tópico discursivo (que neste caso é a classificação dos seres vivos)? Neste caso, o analista iria verificar o plano intratópico, isto é, como se dá a hierarquia entre tópicos e subtópicos; e no intertópico, a linearidade do texto, verificando-se as estratégias de construção textual. Esse tipo de pergunta, nesta perspectiva, seria tratado como pergunta plena, tendo como função o desvelamento do tópico, classificação dos seres vivos.

As de múltipla escolha são perguntas cujas respostas já se acham explicitadas na fala da professora, bastando apenas o aluno escolher uma delas, como em (14).

(14) L1 - é o conjunto de várias ou muitas espécies ... certo? ((L1 faz cada uma das perguntas, apontando no quadro a palavra base para cada uma das respostas, dessa forma, ela consegue prender a atenção dos alunos, que seguem atentamente a indicação)). e se eu perguntar para vocês quem é maior o reino ou a espécie?

\section{L2L3L4 ... o reino .... (p. 6, linha 178)}

A presença de pergunta múltipla escolha tem por objetivo que o aluno escolha apenas uma de duas perguntas, retirando a possibilidade de o aluno responder de outra forma. Neste caso, a resposta do aluno sempre depende

$29 \quad I b d$, p. 77. 
da pergunta da professora. Essas perguntas, muitas vezes, são mal elaboradas, dificultando a reflexão do aluno. Elas apontam apenas para a pergunta que o professor acha correto.

Já as perguntas com lacunas se caracterizam por possuir acento de interrogação no final, dando possibilidade para o aluno responder adequadamente as expectativas da professora, como em (15)

(15) L1 - duas formas... que formas são essas? ... ((L1 já dá uma rápida olhada no relógio, percebendo o fim da aula)) a sexuada é:? Sexuada ok? Como é a

L2[sexuada

forma assexuada? a assexuada? é aquela em que não há o quê?

L2 - ( )

L1 - é feita por um só indivíduo ... ou seja ... não participação de quem?

$\mathrm{L} 2-()$

L1 - não há participação duas?

L2 - gametas... (p. 32, linha 1220)

Pelo que se pode observar, esse tipo de questionamento já traz a evidência da resposta. Não há necessidade de se fazer esforço algum para responder a esse tipo de pergunta.

Fazer uma análise na perspectiva do texto e da interação vai além de uma análise suprasegmental. É nesse tom que Aquino, Andrade e Fávero ${ }^{30}$ consideram que se deva fazer análise não fragmentada, e que dê conta da complexidade dos fatos linguísticos envolvidos na coprodução textual. Assim, em conformidade com as autoras, para se atingir tal objetivo, é preciso responder às seguintes questóes: o que os interlocutores dizem (função), onde dizem (discurso) e como dizem (forma). Por esta abordagem, "explicitam-se as estratégias usadas pelos falantes no processamento do texto, considerando-se também a situação comunicativa e os participantes da interação". ${ }^{31}$

30 AQUINO, Zilda Gaspar de Oliveira; ANDRADE, Maria Lúcia da Cunha Victório de Oliveira; FÁVERO, Leonor Lopes. "Perguntas e respostas como mecanismos de coesão e coerência no texto falado". In: CASTILHO, Ataliba T. de; BASÍLIO, Margarida. Gramática do Português Falado. Vol. IV: Estudos Descritivos. São Paulo: FAPESP, Ed. da UNICAMP, 1996, p. 475.

$31 \mathrm{Ibd}, \mathrm{p} .475$. 
Outro tipo de pergunta proposto é a de animação, que tem como característica animar a aula para que não se torne monótona, provocando os alunos, a fim de que estes participem da aula. Observe-se, em (16), como a professora se dirige aos alunos na tentativa de convencê-los a participar da aula:

(16) L1 - hem gente? quem é que causa a malária? (( desta vez L1 faz a indagação para toda turma, olhando-os insistentemente.))

L2- plasmolium(( a aluna responde num tom muito baixo))

L1 - é o... é o protozoário ou o mosquito? (p. 64, linha 2474)

A professora lançou mão desse tipo de pergunta por estar preocupada com o desenvolvimento da aula, temendo que esta caísse no silêncio, na monotonia. Outra forma de interrogar, de acordo com essa classificação, é a que se usa para verificar o contato. Essa verificação é feita por marcadores discursivos, como 'tá?', 'certo?', 'né?', tendo por finalidade manter uma relação entre o professor e o aluno.

(17) L1 - que eles são procariontes e unicelulares ... eles são formados por uma

L2L3[ celulares

única célula e essa célula não tem um núcleo organizado ... por isso que eles são chamados de PROcariontes ... certo? são essas duas principais características ... né? que classificaram esses dois seres no mesmo reino ... (p.41, linha 1563)

A principal função dos marcadores discursivos ilustrados em (17), da forma como propóe Coracini, ${ }^{32}$ é verificar se os alunos estão prestando atenção e se estão acompanhado o tópico que está em desenvolvimento. Na abordagem textual-interativa, os marcadores discursivos exercem outras funções: a) sequenciar em movimentos coordenados e cooperativos, b) organizar localmente a conversação, c) controlar o encadeamento das funções, e d) constituir-se em elemento proponente do tópico discursivo, seja no nível do super ou do subtópico. ${ }^{33}$

32 CORACINI, op. cit.

33 AQUINO, Zilda Gaspar de Oliveira; ANDRADE, Maria Lúcia da Cunha Victório de Oliveira; FÁVERO, Leonor Lopes. "Perguntas e respostas como mecanismos de coesão e coerência no texto falado”. In: CASTILHO, Ataliba T. de; BASÍLIO, Margarida. Gramática do Português Falado. Vol. IV: Estudos Descritivos. São Paulo: FAPESP, Ed. da UNICAMP, 1996 , p. 476. 
Por fim, tem-se a classificação das perguntas comunicativas, que foram classificadas assim por não terem relação com assunto que está sendo ministrado em sala de aula. A nomenclatura "comunicativa", segundo Coracini, se deu por falta de um termo específico. Essa classificação se justifica também por estarem relacionadas com a linguagem informal, do dia-a-dia, estando fora da relação professor-aluno, e também das questôes didáticas, como em (18).

(18) L1 - ... o paramécio que tem vida livre ele não é parasita ... não é ele é encontrado nos córregos e poças L5[ igual a gente

d'água ... temos também o parafídeo ...

L10 - que horas aí doido?

L11 - três e me:ia: (( responde bocejando.))

L1 - e é exemplo de ESPOROZOÁRIO ... ((soa a cigarra.)) vou terminar ... (p. 63, linha 2445)

Esta pergunta feita pelo aluno não estava relacionada com o tópico em andamento, já que a professora estava discorrendo sobre os paramécios, configurando-se num tipo de pergunta comunicativa, por não ter nenhuma ligação com as questôes didáticas da aula.

\section{Uma abordagem unificada para as perguntas}

Nas seçóes anteriores, mostramos o que se tem produzido na área de pergunta e que são de pertinência para esta pesquisa. Essas classificaçóes dialogam e divergem em alguns pontos, seja na forma de elaboração de cada uma, seja na perspectiva teórica. A proposta de Fávero, Andrade e Aquino ${ }^{34}$ considera as perguntas quanto à função e relaciona com o tópico, assim como a proposta de Freitag e Araujo. ${ }^{35}$ Entretanto, estas além de relacionar as perguntas com o tópico em desenvolvimento, analisam-nas enquanto estratégias de interação e sequenciação na organização textual. Um exemplo desse traço diferencial diz respeito às perguntas retóricas. Fávero, Andrade e Aquino classificam apenas em relação ao tópico, Araujo e Freitag fazem essa relação na organização textual.

$\begin{array}{ll}34 & \text { FÁVERO, et alii, op. cit. } \\ 35 & \text { ARAÚJO; FREITAG, op. cit. }\end{array}$ 
Já Coracini ${ }^{36}$ do mesmo modo, considera as perguntas no que se refere à função, sob o ponto de vista de servir para estabelecer a relação professor-aluno, mediada pelo material didático. Essa classificação não está diretamente relacionada com o desenvolvimento do tópico. Neste caso, o que se nota, em sua proposta, são perguntas que servem à mesma função de Fávero, Andrade e Aquino ${ }^{37}$ e Freitag e Araujo, porém com nomenclatura diferente. Um exemplo diz respeito à classificação das semirretóricas. Para Coracini, estas servem para animar a aula, classificando-a como perguntas de animação. Neste caso, quando um professor faz uma pergunta que ele mesmo responde, o faz para não dar oportunidade ao aluno de responder. Para a autora, essa postura compromete o desenvolvimento crítico do aluno, já que estes acham normal esse procedimento, não procurando, portanto, responder a esse tipo de pergunta; em Araújo e Freitag, ${ }^{38}$ esta função está relacionada com estratégias interativas e sequenciadoras. As perguntas retóricas não aparecem na proposta de Coracini. ${ }^{39}$

A proposta de classificação que é feita aqui tem por base a revisão bibliográfica das abordagens de perguntas, como foi mostrado nas seçôes anteriores, articuladas ao discurso assimétrico do contexto de sala de aula, tomando por ponto de partida as perguntas didáticas da proposta de Coracini, ${ }^{40}$ a partir das quais as outras são classificadas. Todavia, a autora faz esta distinção baseada na relação professor-aluno, tendo em vista o material didático, ou seja, classifica como didáticas as perguntas que seguem esta relação, e em comunicativas, mesmo fazendo parte da aula, as que fogem as questóes didáticas. Apenas as perguntas didáticas são preservadas nesta perspectiva, porém, são focadas em relação à estrutura do tópico discursivo. A classificação em comunicativas para perguntas que não estão relacionadas com o assunto (tópico) recebe outro nome quando a análise se centra no tópico e numa perspectiva do texto e da interação. Logo, esta classificação não é considerada, pois, nesta abordagem; essas perguntas seriam tratadas em relação a suas funçôes: mudança e retomada de tópico.

36 CORACINI, op. cit.

37 FÁVERO, et alii, op. cit.

38 ARAÚJO; FREITAG, op. cit.

39 CORACINI, op. cit.

${ }^{40} \mathrm{Ibd}$. 
A categoria função é estendida para todas as perguntas, por se entender que toda e qualquer pergunta elaborada em sala de aula estabelece alguma função no discurso.

Desta forma, a proposta aqui adotada obedece alguns critérios. Quanto à presença de resposta, as didáticas são classificadas em plenas > semirretóricas > retóricas dentro de um contínuo a partir da gramaticalização dos marcadores discursivos. Quanto à forma da resposta, as perguntas podem ser classificadas em abertas, marcadas linguisticamente, e fechadas, de sim ou não; quanto à forma das perguntas, podem ser encadeadas, múltipla escolha, com lacunas, animação.

São classificadas como comunicativas as perguntas que funcionalmente não estiverem diretamente relacionadas com a estrutura do tópico em andamento em sala de aula. $\mathrm{O}$ quadro 3 sumariza a proposta de classificação das estratégias de interrogação no discurso da sala de aula.

\begin{tabular}{|c|c|c|}
\hline \multicolumn{3}{|c|}{ PROPOSTA DE CLASSIFICAÇÃO PARA SALA DE AULA } \\
\hline \multicolumn{3}{|c|}{ PERGUNTAS DIDÁTICAS } \\
\hline $\begin{array}{c}\text { PRESENÇA DE } \\
\text { RESPOSTA }\end{array}$ & FORMA DE RESPOSTA & FORMA DE PERGUNTA \\
\hline$\downarrow \downarrow \downarrow$ & & \\
\hline & $\begin{array}{c}\text { ABERTAS } \\
\downarrow \\
\text { FECHADAS }\end{array}$ & $\begin{array}{l}\text { - ENCADEADAS } \\
\text { - MÚLTIPLA ESCOLHA } \\
\text { - COM LACUNAS } \\
\text { - ANIMAÇÃO }\end{array}$ \\
\hline
\end{tabular}

Quadro 3: Proposta de classificação das estratégias de interrogação no discurso da sala de aula

Essa classificação contempla os estudos feitos sobre perguntas, ao mesmo tempo em que se busca um ponto de encontro nesses estudos evitando redundâncias, posto que muitas vezes uma pergunta tem a mesma função e recebe uma nomenclatura diferente. 


\section{Considerações finais}

Neste texto, observamos a funcionalidade das perguntas no discurso de sala de aula. Como as estratégias interrogativas, são mecanismos imprescindíveis no discurso do espaço escolar. Porém, faz-se necessário ainda refletir sobre o modo como estas estratégias têm sido utilizadas neste espaço. Dessa forma, este estudo se justifica pela necessidade de se ter conhecimento dos diferentes mecanismos gramatical-discursivos que são utilizados dentro do contexto de interrogação, que foi o que pretendemos demonstrar ao longo deste texto.

A partir das tipologias de perguntas que já foram propostas, tanto no discurso simétrico, como no assimétrico, fizemos um cotejamento entre elas, e chegamos a uma proposta de classificaçáo das perguntas aplicada ao contexto da sala de aula. Constatamos que as perguntas em sala de aula são do tipo de didática que pode ser classificada quanto à presença de resposta em plenas, semirretóricas ou retóricas; quanto à forma da resposta, em abertas, marcadas linguisticamente, e fechadas, de sim ou náo; e quanto à forma podem ser classificadas como encadeadas, múltipla escolha, com lacunas e animação.

Toda essa tipologia é redirecionada pelo fato dos estudos sobre as perguntas ressaltados anteriormente apresentarem traços que dialogam, mas que também divergem em alguns pontos, seja por terem sido efetuados em outra perspectiva teórica, seja pelo fato das perguntas que exercem a mesma função receberem nomenclaturas diferentes.

Esperamos que esta investigação contribua, de alguma forma, para os estudos de interação na sala de aula. E, também, para que professores repensem nas práticas de ensino desenvolvidas ao usarem estas estratégias uma vez que é através delas que se pode chegar ao conhecimento produzido neste ambiente discursivo. Dessa forma, realizar estas estruturas não é algo tão simples como possa se imaginar, muito menos no contexto escolar em que a forma como utilizamos estas estratégias refletem diretamente no processo de ensino-aprendizagem. 


\title{
QUESTIONS IN THE CLASSROOM: A TEXTUAL-INTERACTIVE CLASSIFICATION
}

\begin{abstract}
This text provides an analysis of the use of questions in the classroom, in a textual-interactive approach. Review of the studies that focus interrogative strategies in speech to propose a classification of questions in the classroom discourse.
\end{abstract}

KEYWORDS: interrogative strategies, classroom, discursive practice.

Recebido em: 28/03/12

Aprovado em: 25/11/12 